\title{
THE PROBABILISTIC STABILITY FOR A FUNCTIONAL NONLINEAR EQUATION IN A SINGLE VARIABLE
}

\author{
DOREL MiHeŢ
}

Abstract. We use the fixed point method to prove the probabilistic Hyers-Ulam and generalized Hyers-Ulam-Rassias stability for the nonlinear equation $f(x)=\Phi(x, f(\eta(x)))$ where the unknown is a mapping $f$ from a nonempty set $S$ to a probabilistic metric space $\left(X, F, T_{M}\right)$ and $\Phi: S \times X \rightarrow X, \eta: S \rightarrow X$ are two given functions.

Mathematics subject classification (2000): 39B52, 39B82, 47H10, 54E70.

Keywords and phrases: Functional equation, fixed points, Hyers-Ulam stability, probabilistic metric space.

\section{REFERENCES}

[1] R. P. Agarwal, B. Xu, W. Zhang, Stability of functional equations in single variable, J. Math. Anal. Appl., 288 (2003), 852-869.

[2] T. AokI, On the stability of the linear transformation in Banach spaces, J. M. Soc. Japan, 2 (1950), 64-66.

[3] J. A. BAKER, The stability of certain functional equations, Proc. AMS, 112 (1991), 729-732.

[4] B. BATKO, J. TABOR, Stability of an alternative Cauchy equation on a restricted domain, Aequationes Mathematicae, 57 (1999), 221-232.

[5] D. G. Bourgin, Classes of transformations and bordering transformations, Bull. AMS, 57 (1951), 223-237.

[6] G. L. Cain JR., R. H. Kasriel, Fixed and Periodic Points of Local Contraction Mappings on Probabilistic Metric Spaces, Mathematical Systems Theory, 9, 4 (1976), 289-297.

[7] L. CĂDARIU AND V. RADU, Fixed points and the stability of Jensen's functional equation, Journal Ineq. Pure Appl. Math, 4, 1 (2003), Article 4, 1-7.

[8] L. CĂDARIU, V. RADU, Fixed point method for the generalized stability of functional equations in single variable, Fixed Point Theory and Applications, volume 2008.

[9] S. CZERwIK, Functional Equations and Inequalities in Several Variables, World Scientific, River Edge, NJ, 2002.

[10] G. L. ForTI, Hyers-Ulam stability of functional equations in several variables, Aequationes Math., 50 (1995), 143-190.

[11] P. GĂVRUŢă, A generalization of the Hyers-Ulam-Rassias stability of approximately additive mappings, J. Math. Anal. Appl., 184 (1994), 431-436.

[12] A. Gianyi, Z. Kaiser, Z. Pales, Estimates to the stability of functional equations, Aequationes Math., 73 (2007), 125-143.

[13] O. HADŽIĆ, E. PAP, Fixed Point Theory in PM Spaces, Kluwer Academic Publ., 2001.

[14] D. H. HyeRs, On the stability of the linear functional equation, Proc. Nat. Acad. Sci. USA, 27 (1941), $222-224$.

[15] D. H. Hyers, G. Is AC, Th. M. Rassias, Stability of Functional Equations in Several Variables, Basel, 1998.

[16] D. H. Hyers, G. Is AC, Th. M. Rassias, Topics in Nonlinear Analysis and Applications, World Scientific Publishing Company, Singapore, New Jersey, London, 1997.

[17] I. Istrăţ̧ESCU, On generalized Menger spaces, Boll. UMI, 5, 13-A (1976), 95-100.

[18] C. F. K. JUNG, On generalized complete metric spaces, Bull. A.M.S., 75 (1969), 113-116. 
[19] Y.-S. JUNG, On the stability of the functional equation $f(x+y-x y)+x f(y)+y f(x)=f(x)+f(y)$, Mathematical Inequalities and Appl. MIA, 7, 1 (2004), 79-85.

[20] W. A. J. LuXEMBURG, On the convergence of successive approximations in the theory of ordinary differential equations, II, Nederl. Akad. Wetensch. Proc. Ser. A 61 = Indag. Math., 20 (1958), 540-546.

[21] B. MARGolis, J. B. DiAZ, A fixed point theorem of the alternative for contractions on a generalized complete metric space, Bull. Amer. Math. Soc., 74 (1968), 305-309.

[22] D. Minet, B-contractions on $\sigma$-Menger spaces, Seminar on Probability Theory and Applications (STPA) West Univ. of Timişoara 109 (1994).

[23] D. MiHEŢ, The fixed point method for fuzzy stability of the Jensen functional equation, Fuzzy Sets and Systems, 160 (2009), 1663-1667.

[24] D. MıHEŢ, The probabilistic stability for a functional equation in a single variable, Acta Mathematica Hungarica, 123 (2009), 249-256.

[25] D. Mineţ, V. RADU, A fixed point theorem for mappings with contractive iterate in PM spaces, An. Univ. A. I. Cuza Iaşi, XLII (1996), 311-314.

[26] D. MiHET, V. RADU, On the stability of the additive Cauchy functional equation in random normed spaces, Journal of Mathematical Analysis and Applications, 343 (2008), 567-572.

[27] A. K. Mirmostafaee, M. Mirzavaziri, M. S. Moslehian, Fuzzy stability of the Jensen functional equation, Fuzzy Sets and Systems, 159 (2008), 730-738.

[28] A. K. Mirmostafee, M. S. Moslehian, Fuzzy versions of Hyers-Ulam-Rassias theorem, Fuzzy Sets and Systems, 159, 6 (2008), 720-729.

[29] A. F. MonnA, Sur un theoreme de M. Luxembourg concernant les points fixes d'un classe d'applications d'un espace metrique dans lui meme, Nederl. Akad. Wet., Proc., Ser. A, 64 (1961), $89-96$.

[30] D. Popa, Functional inclusions on square-symmetric grupoids and Hyers-Ulam stability, Mathematical Inequalities and Appl. MIA, 2 (2004), 125-134.

[31] V. RADU, The fixed point alternative and the stability of functional equations, Fixed Point Theory, Cluj-Napoca, IV, 1 (2003), 91-96.

[32] TH. M. Rassias, On the stability of the linear mapping in Banach spaces, Proc. Amer. Math. Soc., 72 (1978), 297-300.

[33] B. SchweIZer, A. Sklar, Probabilistic Metric Spaces, North Holland, 1983.

[34] V. M. Sehgal, A. T. Bharucha-ReId, Fixed points of contraction mappings on PM-Spaces, Math. Syst. Theory, 6 (1972), 97-100.

[35] N. X. Tan, Generalized Probabilistic Metric Spaces and Fixed Point Theorems, Mathematische Nachrichten, 129, 1 (1986), 205-218.

[36] T. TRIF, On the stability of a functional equation deriving from an inequality of Popoviciu for convex functions, Journal of Mathematical Analysis and Applications, 272 (2002), 604-616. 